\title{
Development of Bioartificial Myocardium Using Stem Cells and Nanobiotechnology Templates
}

\author{
Juan Carlos Chachques \\ Department of Cardiovascular Surgery and Laboratory of Biosurgical Research, Pompidou Hospital, University Paris Descartes, \\ 20 rue Leblanc, 75015 Paris, France \\ Correspondence should be addressed to Juan Carlos Chachques, j.chachques@egp.aphp.fr
}

Received 4 October 2010; Accepted 16 November 2010

Academic Editor: Javed Butler

Copyright ( $\odot 2011$ Juan Carlos Chachques. This is an open access article distributed under the Creative Commons Attribution License, which permits unrestricted use, distribution, and reproduction in any medium, provided the original work is properly cited.

\begin{abstract}
Cell-based regenerative therapy is undergoing experimental and clinical trials in cardiology, in order to limit the consequences of decreased contractile function and compliance of damaged ventricles following myocardial infarction. Over 1000 patients have been treated worldwide with cell-based procedures for myocardial regeneration. Cellular cardiomyoplasty seems to reduce the size and fibrosis of infarct scars, limit adverse postischemic remodelling, and improve diastolic function. The development of a bioartificial myocardium is a new challenge; in this approach, tissue-engineered procedures are associated with cell therapy. Organ decellularization for bioscaffolds fabrication is a new investigated concept. Nanomaterials are emerging as the main candidates to ensure the achievement of a proper instructive cellular niche with good drug release/administration properties. Investigating the electrophysiological properties of bioartificial myocardium is the challenging objective of future research, associating a multielectrode network to provide electrical stimulation could improve the coupling of grafted cells and scaffolds with host cardiomyocytes. In summary, until now stem cell transplantation has not achieved clear hemodynamic benefits for myocardial diseases. Supported by relevant scientific background, the development of myocardial tissue engineering may constitute a new avenue and hope for the treatment of myocardial diseases.
\end{abstract}

\section{Introduction}

Ischemic myocardial disease, the main cause of heart failure, is a major public health and economic problem. Given the aging population, heart failure is becoming a bigger clinical issue and bigger financial burden $[1,2]$. Thus, research in heart failure is of relevant interest and importance, involving specialities as cellular and molecular biology, tissue engineering, genetics, biophysics, and electrophysiology.

\section{Cellular Cardiomyoplasty}

The recent progress in cellular and molecular biology allows the development of new therapies for heart failure. One of the most innovative consists in the transplantation of stem cells into the myocardium for heart muscle regeneration. This approach is called "cellular cardiomyoplasty" $[3,4]$. Adult myocardium cannot effectively repair after infarction due to the limited number of stem cells. Thus, most of the injury is irreversible [5]. For this reason, cell transplantation strategies for heart failure have been designed to replace damaged cells with cells that can induce angiogenesis in order to recover hibernating and stunned myocardium or to grow new fibers creating contractile tissue that will perform cardiac work, either in ischemic or nonischemic cardiomyopathies.

Grafting of healthy cells into the diseased myocardium holds enormous potential as an approach to cardiovascular pathology. The functional goal of cell transplantation is to contribute to improve systolic and diastolic ventricular functions and to reverse the postischemic remodeling process responsible for ventricular chambers dilatation [5].

The encouraging results of experimental studies [6-10] have opened the way to the clinical application of cellular cardiomyoplasty in patients with akinetic and nonviable postinfarction scar and low ejection fraction and in patients 
presenting idiopathic and chagasic cardiomyopathies [1114]. Cultured autologous cells do not raise immunological, ethical, tumorogenesis, or donor availability problems. Thus, the development of cell therapy for heart failure is progressing according to a rigorous scientific methodology, from observation to experimentation to a careful evaluation of preliminary clinical results.

Current possibilities in cell therapy for myocardial regeneration are the transplantation into the damaged myocardium of different types of stem cells as autologous myoblasts (originating from a skeletal muscle biopsy) [15], bone marrow stem cells [16], peripheral blood stem cells [17], vascular endothelial cells [18], mesothelial cells (removed from a biopsy of the omentum) [19], adipose tissue stem cells [20], umbilical cord cells, induced pluripotent stem cells (iPSCs), and embryonic pluripotent cells [21]. There is a tendency to use bone marrow cells for myocardial regeneration since this approach avoids the 3-week cellculture procedure and the risk of ventricular arrhythmias and sudden death observed after skeletal myoblast transplantation.

Tissue engineering using biological and synthetic matrix is now associated with cell therapy, the goal is to develop a bioartificial myocardium [22-27]. The MAGNUM Clinical Trial (Myocardial Assistance by Grafting a New Upgraded bioartificial Myocardium) is under development by our group [28].

\section{Indications}

3.1. Ischemic Cardiomyopathy. Clinical application for cell transplantation should be in patients presenting a cardiac dysfunction due to left or right ventricular myocardial infarction. The cells are generally implanted during catheter-based or surgical revascularization procedures. The objective of cellular cardiomyoplasty (CMP) is to limit infarct expansion and cardiac remodelling and regenerate the myocardium. Patients with ischemic mitral valve regurgitation can also be treated with stem cells $[4,29]$.

3.2. Nonischemic Cardiomyopathies. Non ischemic dilated cardiomyopathies and Chagas disease are also major causes of heart failure, with high mortality rates $[2,13]$. Cell transplantation could offer new hopes in this disease by restoring impaired heart function, since the grafted cells appear to better survive in the host myocardium because myocardial irrigation in these pathologies is not severely impaired. Stem cells are injected after catheterization of the coronary arteries. New indications include diabetic and pediatric cardiomyopathies.

\section{Mechanisms of Action}

The many proposed mechanisms of action of cellular cardiomyoplasty are reduction of the size and fibrosis of infarct scars, limitation of adverse postischemic ventricular remodeling, improvement of ventricular wall thickening and compliance, and increase of regional myocardial contractility. Bone marrow cells principally induce angiogenesis and vasculogenesis. Mesenchymal bone marrow cells and induced pluripotent stem cells (iPSCs) are of great interest, since these cells can differentiate in cardiac cells [30].

The initial clinical trials of cell transplantation after a myocardial infarction have reported only limited improvements in ventricular function. Ongoing studies showed survival of the implanted cells, but no study showed active participation of the implanted cells in the force generation. This may be due to the lack of electrophysiological connections between the implanted cells and the host myocardium and lack of the gap junction protein (connexin 43).

In summary, the mechanisms of action of cell therapy seem to be

(i) reduction of the size and fibrosis of infarct scars,

(ii) improvement of myocardial viability,

(iii) limitation of global ventricular dilatation (positive remodelling),

(iv) improvement of ventricular wall compliance and diastolic function,

(v) paracrine effects (antiapoptotic and angiogenic).

\section{Cell Delivery}

The technical approach used to implant the cells should influence the efficacy of cellular CMP. Cell mortality after transplantation seems to be important when they are grafted in the center of high-fibrotic ischemic scars, since there are limitations of oxygen and nutrients supply to the chronic ischemic myocardium. Implanting the cells mainly in the peri-infarct areas may improve the rate of surviving cells, thus the size of the infarct scar may undergo a centripetal reduction [4].

Periodically repeated cell injections should be necessary to progressively reduce the infarct scars in ischemic cardiomyopathies [31] or to gradually improve the diseased myocardium in nonischemic cardiomyopathies. This approach should be boosted by the development of a new generation of specific catheters for percutaneous cell implantations [14].

Intracoronary and endoventricular catheter-based cell delivery procedures for therapeutic angiogenesis and myogenesis have been performed. Nevertheless, the quantity of the cells injected in the target infarcted area is unknown, despite the use of myocardial mapping to identify the pathologic myocardium. The success is largely dependent on many technical considerations namely the risk of cell «regurgitation» at the injection site and the precise localization of the postischemic scar and the peri-infarct areas [14].

A new diagnostic-therapeutic device for local myocardial treatment has been created by our group, called "CELL-FIX" catheter [32]. This system includes a method and apparatus to identify by electrophysiology the infarcted area and to simultaneously deliver the cells, stabilizing by vacuum the scar at the moment of the cell injection with the needle. In 
fact, the Cell-Fix catheter includes a fixing "sucker" system to the endocardium, in the form of a suction cup; this "umbrella" is retracted inside the exterior tube of the distal part of the catheter during the introduction and progression of the device into the arteries. Importantly, during cell delivery the umbrella avoids the risk of ventricular wall perforation by the catheter at the level of the myocardial infarction. This complication was already observed in clinical cases treated with current available catheters.

Experimental studies using the Cell-Fix catheter have demonstrated a minimal loss of the injected material in beating hearts treated after myocardial infarction [32].

\section{Hypoxic Preconditioning of Stem Cells}

Hypoxic preconditioning of stem cells before transplantation into the infarcted heart seems to be useful to promote cell survival and to increase their therapeutic potential. Cell cultures can be performed under low oxygen conditions; flasks can be transferred to a hypoxic incubators (e.g., Xvivo; Biospherix, Lacona, NY), allowing for uninterrupted cell culture and passaging in a controlled atmosphere of $5 \% \mathrm{O}_{2}$ and $5 \% \mathrm{CO}_{2}$ balanced with nitrogen [33]. Under hypoxic conditions, the cells grow faster, thus hypoxia seems to give an initial boost followed by regular stimuli for growth.

Animal studies demonstrated that hypoxic preconditioning enhances the capacity of mesenchymal stem cells to repair infarcted myocardium, attributable to reduced cell death and apoptosis of implanted cells, increased angiogenesis/vascularization, and paracrine effects [34]. In summary, cell preconditioning using reduced oxygen tension to expand cells in the cultures is of relevant interest for the treatment of ischemic heart disease, since these cells could survive better after transplantation in the ischemic myocardium.

\section{Development of Bioartificial Myocardium}

The objective of cellular cardiomyoplasty is to regenerate the myocardium by the implantation of living cells. However, in ischemic disease, the extracellular matrix is also pathologically modified. Therefore, it could be important to associate a procedure aiming at regenerating both myocardial cells and the extracellular matrix. We are currently working to evaluate the potential of a biodegradable tridimensional matrix seeded with cells and grafted onto the infarcted ventricle [22].

Shortly after myocardial infarction, inflammatory cells such as neutrophils, monocytes, and macrophages infiltrate the infarcted zone, and then the necrotic myocytes in the injured myocardium are replaced by collagen fibers. This process uniformly occurs in the whole infarcted area and determines the degree of early infarct expansion. Prevention of the dilation, secondary to LV remodelling, can increase cardiac performance [5].

There are two types of collagen fibers in the normal adult heart, types I and III, produced by fibroblasts and myofibroblasts. The fiber type I represents $80 \%$ of collagen protein in the heart, and type III is near to $10 \%$. These fibers provide structural support and give the heart properties that include stiffness and resistance to deformation; they have also shown an important role as a link between contractile elements of adjacent myocytes, carrying some information useful for cell function. In the infarcted zone, the extracellular myocardial matrix is modified; collagen type I decreases from $80 \%$ to $40 \%$. Experimental and clinical studies performed by our group in ischemic patients showed that bone marrow cell therapy associated with the surgical implantation onto the epicardium of a cell-seeded collagen type I matrix prevented myocardial wall thinning and limited postischemic remodelling $[22,28]$. In addition, collagen matrix as a delivery vehicle significantly reduced the relocation of transplanted MSCs to remote organs and noninfarcted myocardium [35].

\section{Clinical Perspectives}

Followup of congestive heart failure patients has mobilized a growing number of research teams over the past years. Medical treatment particularly with ACE inhibitors combined to beta and aldosterona blockers, heart rate reduction using drugs like Ivabradine [36], and electrophysiological procedures like multisite pacing for atrial-biventricular resynchronization and implantable defibrillators have proven to be effective, improving the prognosis of heart failure patient. However, these treatments remain palliative in many patients, and a lot of cardiovascular diseases still evolve towards the deficiency of the cardiac muscle [1].

Cardiac transplantation remains the only curative treatment of congestive heart failure but has remained limited in its application secondary to shortage of donated organs, age of recipients, and other strict selection criteria. Surgical alternatives for refractory heart failure such as left ventricular geometry/remodeling interventions and dynamic cardiomyoplasty also remain limited in their applicability as well [3, 37]. Cardiomyoplasty, in which the latissimus dorsi muscle is used to create an LV wrap, has been proposed by our group at the earliest $80 \mathrm{~s}$, but nowadays it remains dedicated to patients with right ventricular dysfunction and relatively preserved LV function [38].

Implantable cardiac assist devices are still in evolution. While mechanical support continues to improve, intrinsic disadvantages remain, such as thromboembolism, the need for careful anticoagulation, infection, lack of physiological response, durability, and power supply [39]. Xenotransplantation is in the early phase of research with no clinical applications as of yet.

Historically, tissue regeneration techniques based in cell transplantation technology had been used for the treatment of hemopathies (chronic lymphocytic leukemia, aplastic anaemia, immunodeficiencies, and myeloma), in ophthalmology (transplantation of limbal stem cells for corneal regeneration), and in orthopedics (implantation of chondrocytes for articular defects). Current clinical investigations concern the following specialities: endocrinology (transplantation of stem cells in diabetes mellitus), neurology (Alzheimer and Parkinson diseases), hepatology 
(implantation of hepatocytes as a bridge to liver transplantation), myology (transplantation of myoblasts in Duchenne dystrophy), dermatology (implantation of cultured keratinocytes and fibroblasts in burned patients), and peripheral vascular diseases (implantation of angiogenic stem cells in critical limb ischemia). Transplanted neurally induced embryonic stem cells can differentiate into myelin-forming cells and provide a potential therapy for severely injured peripheral nerves and spinal cord traumatic injury [40].

Engineered organs are in development. Regenerative medicine uses combinations of cells and/or biomaterials to encourage regeneration of healthy tissue and offers an alternative approach for the replacement of lost or deficient organs. Promising results have already been obtained in urology, in children with neurogenic bladder caused by myelomeningocele. Human clinical trials are ongoing in both children and adults to further evaluate the safety and efficacy of this technology for regenerating bladders [41].

The prevalence of severe heart failure and the clear clinical limitations of conventional interventions have encouraged the development of new methods based on the regeneration of the pool of myocardial contractile cells. This approach is supported by recent advances in cellular and molecular biology. New technologies for cell implantation, derived from interventional cardiology procedures, are emerging. Intracoronary and endoventricular catheter-based cell delivery for therapeutic angiogenesis and myogenesis have been performed [14, 16, 17].

Cell transplantation is becoming recognized as a viable strategy to improve myocardial viability and limit infarct growth. The major challenges for future research programs are the preconditioning for predifferentiation of stem cells before transplantation the optimization of the rate of surviving cells after myocardial implantation associating angiogenic therapy (growth factors and/or bone-marrow derived cells) $[42,43]$ with myogenic cells (skeletal muscle cells and bone marrow mesenchymal stem cells) [44].

The improvement of host-cell interactions (mechanical and electrical coupling) is of great importance and interest. To achieve this goal, we have associated electrostimulation (cardiac resynchronization therapy) with stem cell transplantation in ischemic hearts [45]. The development of a bioartificial myocardium is a new challenge; in this approach, tissue engineered procedures are associated with cell therapy $[25,27]$. The preliminary results of the MAGNUM Clinical Trial (Myocardial Assistance by Grafting a New Upgraded bioartificial Myocardium) are encouraging [28] (Figure 1).

\section{Organ Decellularization for Bioscaffold Fabrication}

The use of synthetic and naturally-derived scaffolds for bioengineering of solid organs has been limited due to a lack of an integrated vascular network. Natural bioscaffolds constitute a new approach for tissue engineering. Fabrications of a bioscaffold system with intact vascular tree are in development in specialities such as hepatology, cardiology, and ophthalmology. Animal-donor organs and tissues have been perfused with decellularization solutions to selectively remove the cellular component of the tissue and leave an intact extracellular matrix and vascular network. The vascular tree demonstrated sequential fluid flow through a central inlet vessel that branched into an extensive capillary bed and coalesced back into a single outlet vessel.

9.1. Hepatology. Human liver cells have been used to engineer miniature livers. These livers successfully function in a laboratory setting like human livers. To engineer the organ, animal livers were treated with a mild detergent to remove all cells; this process is called decellularization, leaving only the collagen "skeleton" or support structure. The original cells are then replaced with two types of cells: immature liver cells known as progenitors and endothelial cells that line blood vessels. The cells were introduced into the liver skeleton through a large vessel that feeds a system of smaller vessels in the liver. This network of vessels remains intact after the decellularization process. The liver is next placed in a bioreactor, a special equipment that provides a constant flow of nutrients and oxygen throughout the organ. After a week in the bioreactor system, it was documented the progressive formation of human liver tissue, as well as liverassociated function. This results in a widespread cell growth inside the bioengineered organ. The engineered organs can be grown from the patients' own cells, so there is no risk of rejection. Bioengineered livers could also be useful for evaluating the safety of new drugs; this approach would more closely mimic drug metabolism in the human liver [46].

9.2. Cardiology. A bioartificial heart is a theoretical alternative to transplantation or mechanical left ventricular support. Generating a bioartificial heart requires engineering of cardiac architecture, appropriate cellular constituents, and pump function. Hearts were decellularized by coronary perfusion with detergents, preserving the underlying extracellular matrix, and producing an acellular, perfusable vascular architecture, competent acellular valves, and intact chamber geometry. To mimic cardiac cell composition, these constructs were reseeded with cardiac or endothelial cells. Constructs were maintained for up to 28 days by coronary perfusion in a bioreactor that simulated cardiac physiology. At day 4, macroscopic contractions were observed. At day 8 , under physiological load and electrical stimulation, constructs generated pump function (equivalent to about $2 \%$ of adult or $25 \%$ of 16 -week fetal heart function) in a modified working heart preparation [47].

9.3. Ophthalmology. Corneal transplantation is a common transplant procedure performed to improve visual acuity by replacing the opaque or distorted host tissue by clear healthy donor tissue. However, its clinical utility is limited due to a lack of high-quality donor corneas. Bioengineered neocorneas, created using an expandable population of human donor-derived corneal endothelial cells (HCECs), address this current shortage. Studies were performed to investigate the feasibility of bioengineering corneal tissue constructs by 


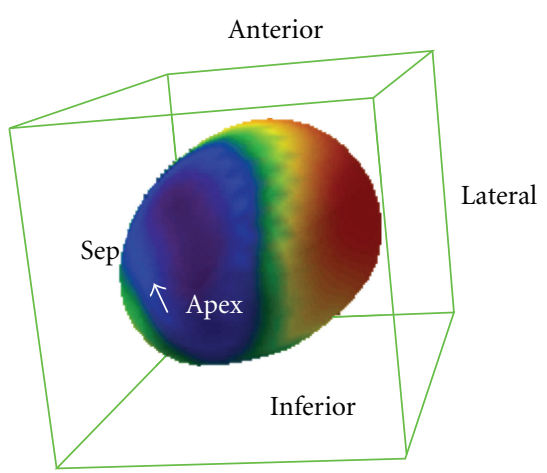

(a)

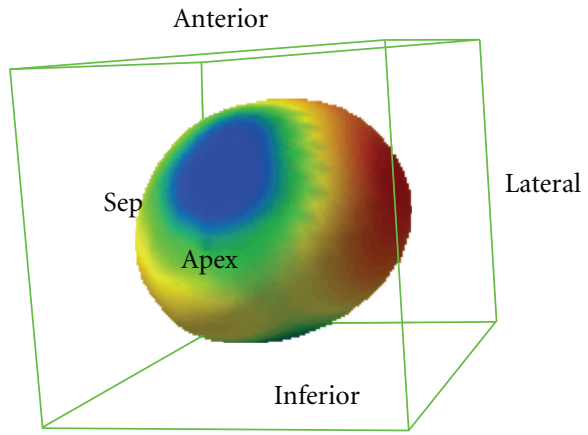

(b)

Figure 1: (a) MAGNUM Clinical Trial: Ischemic heart disease patient, 3D representation of the preoperative radioisotopic SPECT Tc ${ }^{99 m}$ sestamibi imaging, showing the chronic infarction area (blue stain). (b) Same patient, followup at 18 months showing the improvement of myocardial viability and function ( $60 \%$ of reduction of the infarcted area, in blue) after stem cell therapy associated with the implantation onto the infarct scar of a cell-seeded collagen matrix.

seeding the cells on decellularized human corneal stroma. HCECs were removed from the discarded corneas of eye donors by enzymatic digestion. Donor corneal stromas were cut to $120-200$ microm thickness slices using a microtome and then decellularized. To engineer neocorneas, HCECs were seeded on decellularized human corneal stromas. The resulting constructs were placed in growth medium for 14 days. Seeded cells retain expression of the functional markers $\mathrm{Na}(+) / \mathrm{K}(+)$-ATPase and zona occludens $\mathrm{ZO}-1$; in addition, constructs demonstrated biomechanical properties similar to those of normal corneas. These results indicate that construction of neocorneas, using HCECs derived from discarded donor corneas and decellularized thin-layer corneal stromas, may create a new source of high-quality corneal tissue for transplantation [48].

In summary, all these studies demonstrate a novel yet simple and scalable method to obtain whole organvascularized bioscaffolds with potential for liver, kidney, heart, pancreas, intestine, and other organs' bioengineering. These bioscaffolds can further provide a tool to study cells in their natural three-dimensional environment, which is superior for drug discovery platform compared with cells cultured in two-dimensional petridishes.

\section{Bioengineered Cardiac Nanobiomaterials}

Until now, the optimal cell-matrix combination for robust and sustained myocardial restoration has not been identified. We are evaluating bioengineered nanobiomaterials with polymer-based elastomeric membranes to obtain a controlled drug release myocardium patch with additional features, such as local cell attraction (proangiogenic activity) and cell differentiation and delivery (precardiomyocytes). Random injections of stem cells into the heart have proven rather insufficient due to poor cell retention and survival. In order to engraft and function more effectively, bioengineered tissues require some degree of early vascularisation. Hence, more evolved tissue constructs must be produced involving more efficient vascularisation strategies.
Our group is developing a bioengineered platform consisting in obtaining preconditioned electrostimulated stem cells to resist their implantation into a highly stressed tissue [49]. Cells are incorporated in this newly designed biodegradable scaffolds that will support cell survival, proper cardiomyogenic differentiation, and early extracellular instruction. This construct should induce vascularisation to ensure rapid tissue remodelling and regeneration into a newly functional myocardium.

Good progress in the design and fabrication of synthetic biomaterials with biomimetic characteristics has been accomplished in the field of nanotechnology for direct applications in biomedicine. The main purpose of these materials is to display structural and functional properties similar to extracellular matrices, containing truly threedimensional nanonetworks and eventual control in the delivery and effective concentration of "therapeutic drugs" [50-52].

Nanomaterials are emerging as the main candidates to ensure the achievement of a proper instructive cellular niche with good drug release/administration properties. Synthetic nanomaterials are attractive platforms because of their pure composition, predictive toxicology, target specificity, low manufacturing costs, and control in degradability. Proteins, peptides, and polysaccharides are top on the list for their versatility in nanomaterial design and fabrication $[53,54]$.

Investigating the electrophysiological properties of bioartificial myocardium is the challenging objective of future research. A multielectrode network to provide electrical stimulation could be included in order to improve the coupling of grafted stem cells and scaffolds with host cardiomyocytes, the goal being to improve the local properties of ischemic myocardium. In summary, until now stem cell transplantation has not achieved clear hemodynamic benefits for myocardial diseases [55]. Supported by relevant scientific background, the development of myocardial tissue engineering may constitute a new avenue and hope for the treatment of myocardial diseases $[56,57]$. 


\section{References}

[1] M. Jessup and S. Brozena, "Heart failure," The New England Journal of Medicine, vol. 348, no. 20, pp. 2007-2018, 2003.

[2] G. S. Bleumink, A. M. Knetsch, M. C. J. M. Sturkenboom et al., "Quantifying the heart failure epidemic: prevalence, incidence rate, lifetime risk and prognosis of heart failurethe Rotterdam Study," European Heart Journal, vol. 25, no. 18, pp. 1614-1619, 2004.

[3] J. C. Chachques, A. Shafy, F. Duarte et al., "From dynamic to cellular cardiomyoplasty," Journal of Cardiac Surgery, vol. 17, no. 3, pp. 194-200, 2002.

[4] J. C. Chachques, C. Acar, J. Herreros et al., "Cellular cardiomyoplasty: clinical application," Annals of Thoracic Surgery, vol. 77, no. 3, pp. 1121-1130, 2004.

[5] M. A. Pfeffer and E. Braunwald, "Ventricular remodeling after myocardial infarction: experimental observations and clinical implications," Circulation, vol. 81, no. 4, pp. 1161-1172, 1990.

[6] J. S. Wang, D. Shum-Tim, J. Galipeau, E. Chedrawy, N. Eliopoulos, and R. C. J. Chiu, "Marrow stromal cells for cellular cardiomyoplasty: feasibility and potential clinical advantages," Journal of Thoracic and Cardiovascular Surgery, vol. 120, no. 5, pp. 999-1006, 2000.

[7] D. Orlic, J. Kajstura, S. Chimenti et al., "Mobilized bone marrow cells repair the infarcted heart, improving function and survival," Proceedings of the National Academy of Sciences of the United States of America, vol. 98, no. 18, pp. 1034410349, 2001.

[8] D. A. Taylor, B. Z. Atkins, P. Hungspreugs et al., "Regenerating functional myocardium: improved performance after skeletal myoblast transplantation," Nature Medicine, vol. 4, no. 8, pp. 929-933, 1998.

[9] C. Rajnoch, J. C. Chachques, A. Berrebi, P. Bruneval, M. O. Benoit, and A. Carpentier, "Cellular therapy reverses myocardial dysfunction," Journal of Thoracic and Cardiovascular Surgery, vol. 121, no. 5, pp. 871-878, 2001.

[10] C. M. Verfaillie, R. Schwartz, M. Reyes, and Y. Jiang, "Unexpected potential of adult stem cells," Annals of the New York Academy of Sciences, vol. 996, pp. 231-234, 2003.

[11] J. C. Chachques, B. Cattadori, J. Herreros et al., "Treatment of heart failure with autologous skeletal myoblasts," Herz, vol. 27, no. 7, pp. 570-578, 2002.

[12] H. K. Haider, A. C. K. Tan, S. Aziz, J. C. Chachques, and E. K. W. Sim, "Myoblast transplantation for cardiac repair: a clinical perspective," Molecular Therapy, vol. 9, no. 1, pp. 14-23, 2004.

[13] F. Vilas-Boas, G. S. Feitosa, M. B. P. Soares et al., "Early results of bone marrow cell transplantation to the myocardium of patients with heart failure due to chagas disease," Arquivos Brasileiros de Cardiologia, vol. 87, no. 2, pp. 159-166, 2006.

[14] E. C. Perin, H. F. R. Dohmann, R. Borojevic et al., "Transendocardial, autologous bone marrow cell transplantation for severe, chronic ischemic heart failure," Circulation, vol. 107, no. 18 , pp. 2294-2302, 2003.

[15] J. C. Chachques, J. Herreros, J. Trainini et al., "Autologous human serum for cell culture avoids the implantation of cardioverter-defibrillators in cellular cardiomyoplasty," International Journal of Cardiology, vol. 95, no. 1, pp. S29-S33, 2004.

[16] C. Stamm, B. Westphal, H. D. Kleine et al., "Autologous bonemarrow stem-cell transplantation for myocardial regeneration," The Lancet, vol. 361, no. 9351, pp. 45-46, 2003.

[17] V. Schächinger, B. Assmus, M. B. Britten et al., "Transplantation of progenitor cells and regeneration enhancement in acute myocardial infarction: final one-year results of the
TOPCARE-AMI trial," Journal of the American College of Cardiology, vol. 44, no. 8, pp. 1690-1699, 2004.

[18] D. A. Narmoneva, R. Vukmirovic, M. E. Davis, R. D. Kamm, and R. T. Lee, "Endothelial cells promote cardiac myocyte survival and spatial reorganization: implications for cardiac regeneration," Circulation, vol. 110, no. 8, pp. 962-968, 2004.

[19] B. Bourahla, A. Shafy, O. Meilhac, I. Elmadbouh, J. B. Michel, and J. C. Chachques, "Mesothelial cells vs. skeletal myoblasts for myocardial infarction," Asian Cardiovascular and Thoracic Annals, vol. 18, no. 2, pp. 153-160, 2010.

[20] V. Planat-Bénard, C. Menard, M. André et al., "Spontaneous cardiomyocyte differentiation from adipose tissue stroma cells," Circulation Research, vol. 94, no. 2, pp. 223-229, 2004.

[21] I. Kehat, L. Khimovich, O. Caspi et al., "Electromechanical integration of cardiomyocytes derived from human embryonic stem cells," Nature Biotechnology, vol. 22, no. 10, pp. 1282-1289, 2004.

[22] M. Cortes-Morichetti, G. Frati, O. Schussler et al., "Association between a cell-seeded collagen matrix and cellular cardiomyoplasty for myocardial support and regeneration," Tissue Engineering, vol. 13, no. 11, pp. 2681-2687, 2007.

[23] I. Kutschka, I. Y. Chen, T. Kofidis et al., "Collagen matrices enhance survival of transplanted cardiomyoblasts and contribute to functional improvement of ischemic rat hearts," Circulation, vol. 114, no. 1, pp. I167-I173, 2006.

[24] O. Schussler, C. Coirault, M. Louis-Tisserand et al., "Use of arginine-glycine-aspartic acid adhesion peptides coupled with a new collagen scaffold to engineer a myocardium-like tissue graft," Nature Clinical Practice Cardiovascular Medicine, vol. 6, no. 3, pp. 240-249, 2009.

[25] T. Eschenhagen and W. H. Zimmermann, "Engineering myocardial tissue," Circulation Research, vol. 97, no. 12, pp. 1220-1231, 2005.

[26] T. Kofidis, P. Akhyari, J. Boublik et al., "In vitro engineering of heart muscle: artificial myocardial tissue," Journal of Thoracic and Cardiovascular Surgery, vol. 124, no. 1, pp. 63-69, 2002.

[27] J. Leor and S. Cohen, "Myocardial tissue engineering: creating a muscle patch for a wounded heart," Annals of the New York Academy of Sciences, vol. 1015, pp. 312-319, 2004.

[28] J. C. Chachques, J. C. Trainini, N. Lago, M. Cortes-Morichetti, O. Schussler, and A. Carpentier, "Myocardial assistance by grafting a new bioartificial upgraded myocardium (MAGNUM trial): clinical feasibility study," Annals of Thoracic Surgery, vol. 85, no. 3, pp. 901-908, 2008.

[29] C. Spadaccio, E. Chachques, M. Chello, E. Covino, J. C. Chachques, and J. Genovese, "Predifferentiated adult stem cells and matrices for cardiac cell therapy," Asian Cardiovascular and Thoracic Annals, vol. 18, no. 1, pp. 79-87, 2010.

[30] K. Takahashi, K. Tanabe, M. Ohnuki et al., "Induction of pluripotent stem cells from adult human fibroblasts by defined factors," Cell, vol. 131, no. 5, pp. 861-872, 2007.

[31] J. J. Gavira, E. Nasarre, G. Abizanda et al., "Repeated implantation of skeletal myoblast in a swine model of chronic myocardial infarction," European Heart Journal, vol. 31, no. 8, pp. 1013-1021, 2010.

[32] J. C. Chachques, A. Azarine, E. Mousseaux, M. El Serafi, M. Cortes-Morichetti, and A. F. Carpentier, "MRI evaluation of local myocardial treatments: epicardial versus endocardial (Cell-Fix catheter) injections," Journal of Interventional Cardiology, vol. 20, no. 3, pp. 188-196, 2007.

[33] T. Fink, L. Abildtrup, K. Fogd et al., "Induction of adipocytelike phenotype in human mesenchymal stem cells by hypoxia," Stem Cells, vol. 22, no. 7, pp. 1346-1355, 2004. 
[34] X. Hu, S. P. Yu, J. L. Fraser et al., "Transplantation of hypoxiapreconditioned mesenchymal stem cells improves infarcted heart function via enhanced survival of implanted cells and angiogenesis," Journal of Thoracic and Cardiovascular Surgery, vol. 135 , no. 4, pp. 799-808, 2008.

[35] W. Dai, S. L. Hale, G. L. Kay, A. J. Jyrala, and R. A. Kloner, "Delivering stem cells to the heart in a collagen matrix reduces relocation of cells to other organs as assessed by nanoparticle technology," Regenerative Medicine, vol. 4, no. 3, pp. 387-395, 2009.

[36] M. Böhm, K. Swedberg, M. Komajda et al., "Heart rate as a risk factor in chronic heart failure (SHIFT): the association between heart rate and outcomes in a randomised placebocontrolled trial," The Lancet, vol. 376, no. 9744, pp. 886-894, 2010.

[37] A. Carpentier, J. C. Chachques, and P. Grandjean, Eds., Cardiac Bioassist, Futura Publishing, New York, NY, USA, 1997.

[38] J. C. Chachques, P. G. Argyriadis, G. Fontaine et al., "Right ventricular cardiomyoplasty: 10-year follow-up," Annals of Thoracic Surgery, vol. 75, no. 5, pp. 1464-1468, 2003.

[39] L. W. Stevenson, L. W. Miller, P. Desvigne-Nickens et al., "Left ventricular assist device as destination for patients undergoing intravenous inotropic therapy: a subset analysis from REMATCH (Randomized Evaluation of Mechanical Assistance in Treatment of Chronic Heart Failure)," Circulation, vol. 110, no. 8, pp. 975-981, 2004.

[40] L. Cui, J. Jiang, L. Wei et al., "Transplantation of embryonic stem cells improves nerve repair and functional recovery after severe sciatic nerve axotomy in rats," Stem Cells, vol. 26, no. 5, pp. 1356-1365, 2008.

[41] R. Soler, C. Fullhase, and A. Atala, "Regenerative medicine strategies for treatment of neurogenic bladder," Therapy, vol. 6, no. 2, pp. 177-184, 2009.

[42] J. C. Chachques, F. Duarte, B. Cattadori et al., "Angiogenic growth factors and/or cellular therapy for myocardial regeneration: a comparative study," Journal of Thoracic and Cardiovascular Surgery, vol. 128, no. 2, pp. 245-253, 2004.

[43] D. W. Losordo and S. Dimmeler, "Therapeutic angiogenesis and vasculogenesis for ischemic disease: part I: angiogenic cytokines," Circulation, vol. 109, no. 21, pp. 2487-2491, 2004.

[44] K. A. T. Carvalho, L. C. Guarita-Souza, C. L. K. Rebelatto et al., "Could the coculture of skeletal myoblasts and mesenchymal stem cells be a solution for postinfarction myocardial scar?" Transplantation Proceedings, vol. 36, no. 4, pp. 991-992, 2004.

[45] A. Shafy, T. Lavergne, C. Latremouille, M. Cortes-Morichetti, A. Carpentier, and J. C. Chachques, "Association of electrostimulation with cell transplantation in ischemic heart disease," Journal of Thoracic and Cardiovascular Surgery, vol. 138, no. 4, pp. 994-1001, 2009.

[46] P. M. Baptista, G. Orlando, S. H. Mirmalek-Sani, M. Siddiqui, A. Atala, and S. Soker, "Whole organ decellularization-a tool for bioscaffold fabrication and organ bioengineering," in Proceedings of the 31st Annual International Conference of the IEEE Engineering in Medicine and Biology Society (EMBC'09), pp. 6526-6529, September 2009.

[47] H. C. Ott, T. S. Matthiesen, S. K. Goh et al., "Perfusiondecellularized matrix: using nature's platform to engineer a bioartificial heart," Nature Medicine, vol. 14, no. 2, pp. 213 221, 2008.

[48] J. S. Choi, J. K. Williams, M. Greven et al., "Bioengineering endothelialized neo-corneas using donor-derived corneal endothelial cells and decellularized corneal stroma," Biomaterials, vol. 31, no. 26, pp. 6738-6745, 2010.
[49] J. A. Genovese, C. Spadaccio, E. Chachques et al., "Cardiac pre-differentiation of human mesenchymal stem cells by electrostimulation," Frontiers in Bioscience, vol. 14, pp. 29963002, 2009.

[50] S. Chen, S. Hilcove, and S. Ding, "Exploring stem cell biology with small molecules," Molecular BioSystems, vol. 2, no. 1, pp. 18-24, 2006.

[51] C. E. Semino, "Can we build artificial stem cell compartments?" Journal of Biomedicine and Biotechnology, vol. 3, pp. 164-169, 2003.

[52] J. C. Rodríguez Hernández, M. S. Sánchez, J. M. Soria, J. L. Gómez Ribelles, and M. M. Pradas, "Substrate chemistrydependent conformations of single laminin molecules on polymer surfaces are revealed by the phase signal of atomic force microscopy," Biophysical Journal, vol. 93, no. 1, pp. 202207, 2007.

[53] E. Genové, C. Shen, S. Zhang, and C. E. Semino, "The effect of functionalized self-assembling peptide scaffolds on human aortic endothelial cell function," Biomaterials, vol. 26, no. 16, pp. 3341-3351, 2005.

[54] J. C. Rodríguez Hernández, A. Serrano Aroca, J. L. Gómez Ribelles, and M. Monleón Pradas, "Three-dimensional nanocomposite scaffolds with ordered cylindrical orthogonal pores," Journal of Biomedical Materials Research Part B, vol. 84, no. 2, pp. 541-549, 2008.

[55] S. N. Zhang, A. J. Sun, J. B. Ge et al., "Intracoronary autologous bone marrow stem cells transfer for patients with acute myocardial infarction: a meta-analysis of randomised controlled trials," International Journal of Cardiology, vol. 136, no. 2, pp. 178-185, 2009.

[56] E. C. Martinez and T. Kofidis, "Myocardial tissue engineering: the quest for the ideal myocardial substitute," Expert Review of Cardiovascular Therapy, vol. 7, no. 8, pp. 921-928, 2009.

[57] J. C. Chachques, "Cellular cardiac regenerative therapy in which patients?" Expert Review of Cardiovascular Therapy, vol. 7, no. 8, pp. 911-919, 2009. 


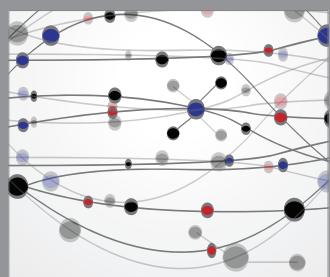

The Scientific World Journal
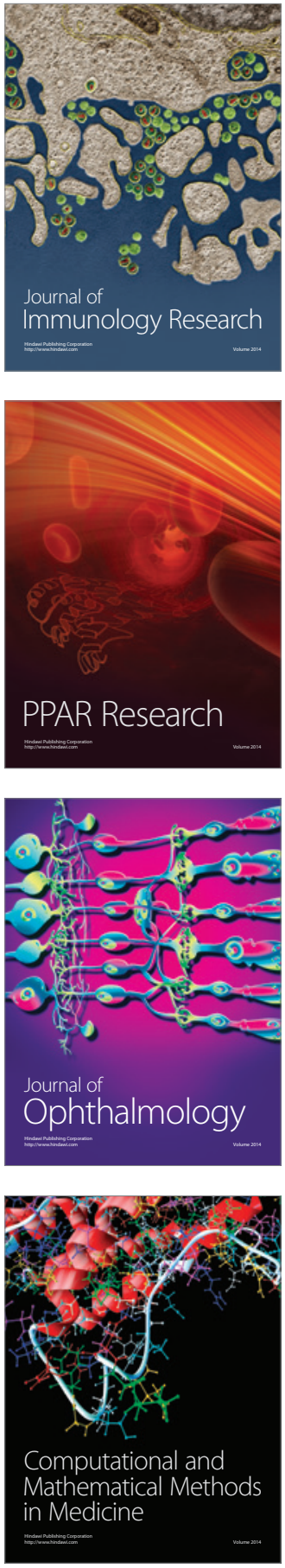

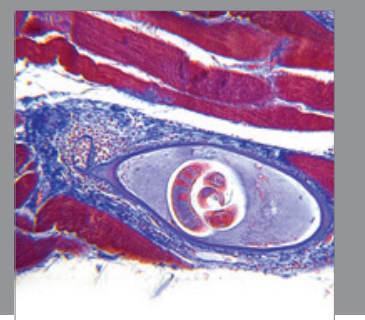

Gastroenterology

Research and Practice
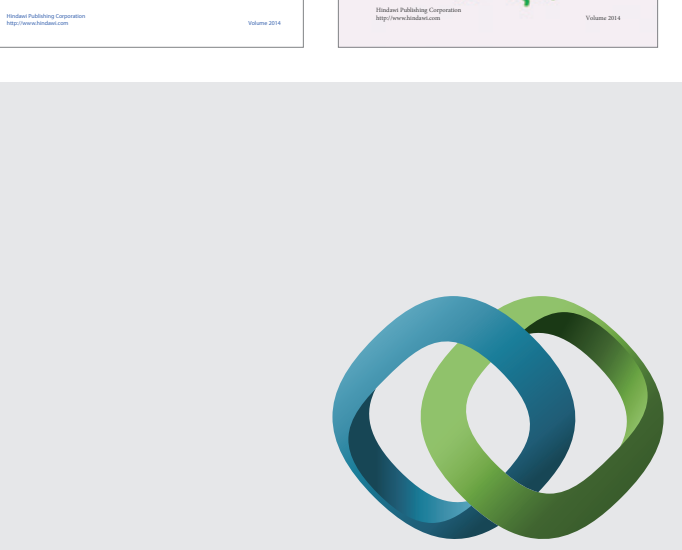

\section{Hindawi}

Submit your manuscripts at

http://www.hindawi.com
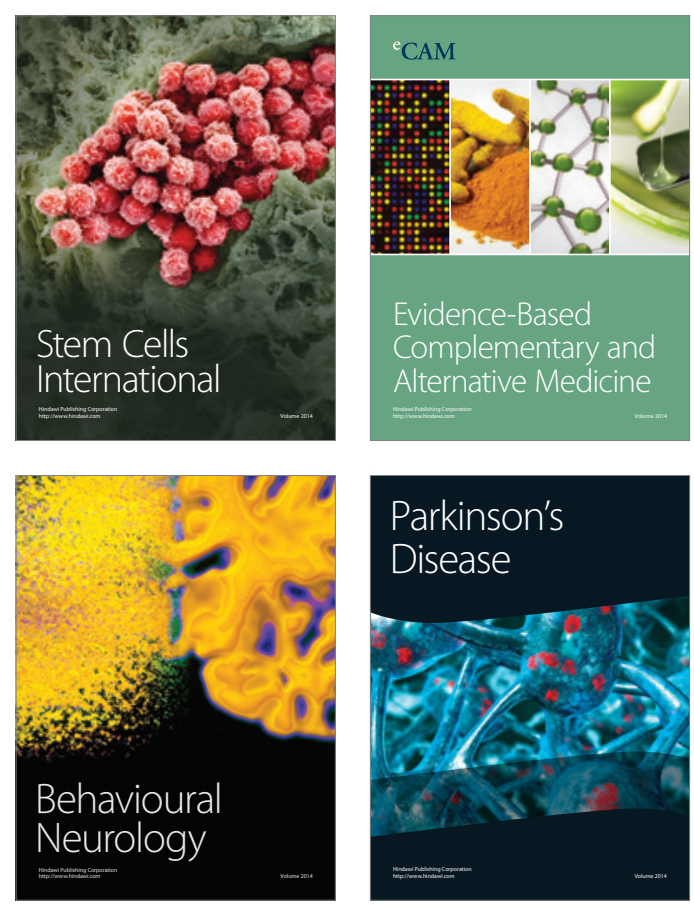

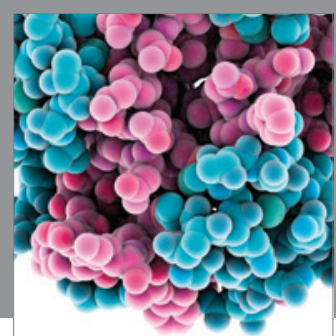

Journal of
Diabetes Research

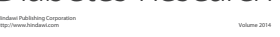

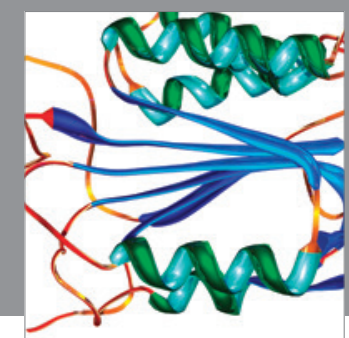

Disease Markers
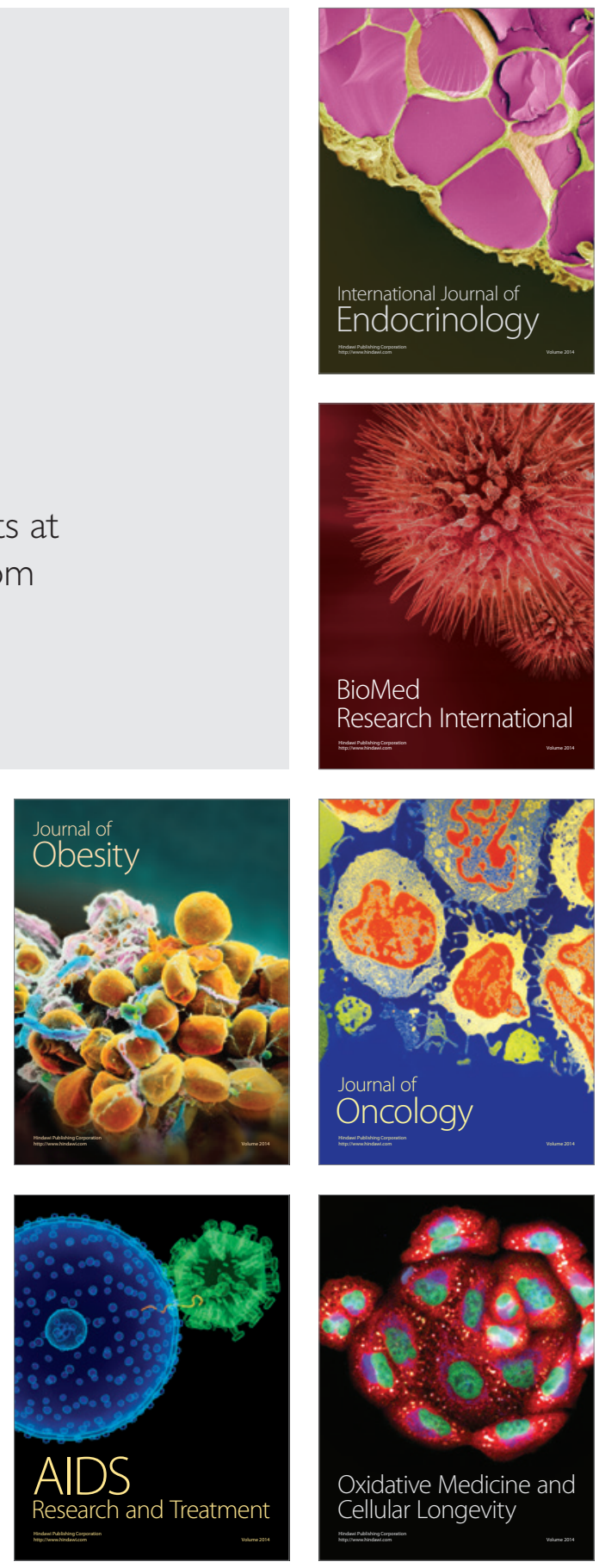